\title{
sciendo
}

Folia Oeconomica Stetinensia

Volume 20 (2020) Issue 2

DOI: $10.2478 /$ foli-2020-0057
WYDZIAL NAUK EKONOMICZNYCH I ZARZĄDZANIA

\section{CULTURAL DETERMINANTS OF SOCIAL MEDIA USE IN WORLD MARKETS}

Elżbieta Wąsowicz-Zaborek, Ph.D.

SGH Warsaw School of Economics

Collegium of World Economy

Institute of International Management and Marketing, Chair of International Business

al. Niepodległości 162, 02-554 Warszawa, Poland

e-mail: ewasowi@sgh.waw.pl

ORCID: 0000-0001-8422-4383

Received 8 January 2020, Accepted 2 April 2020

\begin{abstract}
Research background: Ongoing globalization has led companies to operate on foreign markets and in consequence to recognize very different conditions especially in terms of sociocultural factors. The literature review identifies the behavioral patterns in social media (SM) usage determined by national cultures.

Purpose: The article presents the relationship between six dimensions of national culture defined by Hofstede and the use of SM in world markets.

Research mmethodology: To determine how national culture influences the frequency of use of SM, a study of secondary data was carried out. The percentage of SM users from the Global Digital Yearbook 2019 was used as a dependent variable. The statistical analysis links cultural dimensions with SM use in 44 countries. Results: The study employed polynomial regression, which revealed a significant correlation between long-term orientation, individualism, uncertainty avoidance, and the percentage of SM users. However, the research discovered no influence of masculinity, leniency, and power distance. The estimated models also show the income's strong moderating effect on the analyzed relationship.

Novelty: In this study a deeper analysis of the relationship between the dimensions of national cultures and the use of SM was made than in previous studies. It was also shown that it is necessary to introduce moderating factors, which may significantly affect the relationship between the use of SM and some dimensions of culture.
\end{abstract}

Keywords: social media, cultural dimensions, national culture, polynomial regression

JEL classification: F2, M3 


\section{Introduction}

According to the report Digital 2019: Global Digital Yearbook, 3.48 billion people used social media in the first months of 2019, and the number of users worldwide grew by 288 million (9\%) compared to 2018.

Social media (SM) are online platforms that allow users to interact, share, and create content sustainable and thus are visible to all. While presentations, forms of expression, and technical solutions greatly vary between services, they all exponentially increase content generation. SM is currently the fastest growing marketing channel in the world used both in communication and product distribution. Due to the diversity of SM, it is a difficult task to develop a strategy for the effective targeting and engagement of users.

Ongoing globalization has led companies to operate on foreign markets. The situation necessitates companies to recognize very different operating conditions in terms of economic, technological, natural, political, legal, demographic, and sociocultural factors. The last of the factors evades identification. What scholars usually observe are only external manifestations of culture, which may be difficult to interpret. For the effectiveness of marketing activities, one must first determine how culture influences attitudes on target markets.

Culture refers to a group of people who share values, moral standards, and customs, along with written and spoken language (Hsu, Chang, Lin, Lin, 2015). Studies usually perceive culture as a collective phenomenon. People learn patterns of thinking, feeling, and potential for action by living in a specific social environment, usually typical for a country. This partly determines their behaviors and preferences. Hofstede and Hofstede (2007) define national culture as "the collective programming of the mind that distinguishes members of one group or category from members of another."

As a result of complexity and cultural identity, individuals who represent different cultural systems communicate in different ways (Shachaf, 2007). Online communication also does not work in a cultural vacuum, and cyberspace can strictly reflect the cultural aspects of the offline context in which communication is rooted (Halavais, 2000; Ess, Sudweeks, 2005).

Researchers have identified and analyzed different dimensions of culture. The most discussed and used to describe cultural differences is Hofstede's concept, which indicates six dimensions: power distance (large/small), collectivism-individualism, masculinity-femininity, avoidance of uncertainty (strong/weak), orientation (long/short-term), and restraint-indulgence (Hofstede 1983; Hofstede, Bond; 1988; Hofstede Insights, 2019). Below, these dimensions and their relationship to MS will be described in detail. 


\section{The dimensions of a national culture and research hypotheses}

\subsection{Individualism (IND) and collectivism}

The levels of individualism and collectivism are linked to the environment and social ties between the individual and the group (Hofstede, 2000). This dimension indicates whether culture cares about the well-being of a group and about intergroup relations. High IND cultures take an individual perspective into the account of each decision (Hofstede, 2000; Brewer, Venaik, 2011). IND manifests itself in the recognition of individual goals and achievements, high quality of life linked to personal achievements and successes, and weak bonds between individuals (Schwartz 1994; Hofstede, 2000; Hyrokawa, Dohi, Vannieuwennhuyse, Miyata, 2001; Leibbrandt, Gneezy, List, 2013). Since high IND cultures perceive the needs, goals, and values of individuals as superior to that of a group, people in individualistic countries learn to focus on independence and individual achievement at a young age (Gudykunst, 1997; Hofstede, 1983); for instance, in the Netherlands and Italy.

Collectivist cultures (e.g. Latin America, Central and Eastern Europe, Korea, Thailand, Malaysia, China, Portugal, Greece) are characterized by a strong need to perceive the individual as part of the group (Hofstede, 2000). Ties between individuals in these cultures are closer while their members prefer group work and take great care of each other (Hofstede, 1983; Leonard et. al., 2011).

Communication in collectivist cultures stems from setting the content of a message in a broader context. Recipients require contextual clues to correctly interpret the message and constantly search for them in communication. Clarity and precision of the message are important to individualistic cultures. The message should be clear and straightforward (Gudykunst, 1997).

According to Goodrich and de Mooijb (2013), relationship-oriented collectivist cultures rely on SM more, as they offer an alternative to personal contacts; this allows each person to adapt their message to a specific audience. Therefore, SM that enable the transfer of a lot of information in one place with multiple means of expression (content, image, sound) and the appropriate design of user profiles will probably attract more interest in collectivist cultures. A shorter but more intensive message will be more appropriate for audiences from individualist cultural backgrounds, thus:

H1: Collectivist cultures use SM more frequently. 


\subsection{Uncertainty Avoidance (UA)}

The level of uncertainty avoidance means the tolerance of unspecified and unforeseeable future events (Hofstede, 1983; Gudykunst, 1997). UA does not mean risk avoidance (Hofstede, 2011). Uncertainty is defined as an unknown and unspecified event, while risk is described as specific, so that risk-taking decisions can be made more consciously.

Principles play a crucial role in UA. Thus, a highly UA-rated culture like Spain or Greece seeks regulations, rituals, and rules to guide the daily life and activities of each individual (Gudykunst, 1997; Soares Farhangmehr, Shoham, 2007). Furthermore, we may assume that UA-prone cultures are less likely to accept risk and perceive any unforeseen incidents or unplanned action, improvisation, or fluctuation as a threat (Kravkovich, 2014). Meanwhile, cultures with a low level of UA (e.g. Denmark, USA) accept risk, difference, and inconsistency and welcome changes and innovations (Gudykunst, 1997; Soares et al., 2007; Leonard et al. 2011).

The link between the UA level and SM behavior suggests we should pay attention to certain specific features. In particular, Hermeking (2006) combines a low UA level with greater adaptability to innovation and new forms of communication, such as the Internet and new media. Second, Gudykunst (1997) stresses that communities with a low UA level show more emotions online and interact with individuals outside of their own group. On the other hand, cultures with a strong UA level generally appreciate direct information, as it reduces perceived uncertainty. Moreover, the UA level influences the need and willingness to collect information about other people (Gudykunst, 1997), therefore:

H2: A high UA level is associated with a high rate of SM use.

\subsection{Power Distance (PD)}

The power distance dimension focuses on the relations between superiors and subordinates. According to Tavanti (2012), one of the main principles of PD is the acceptance and conviction that some people have more power than others in society. A high level of PD significantly emphasizes hierarchical relations and status privileges (Leonard et al., 2011). Thus, PD expresses the conditions under which a society accepts inequalities and authority and awaits recommendations from the top (Gudykunst, 1997; Hofstede, 2000; Leonard et al., 2011; Tavanti, 2012).

External manifestations of a high level of PD will be respect for superiors and those in higher positions, along with the manifestation of degrees, titles, and positions. Examples of countries with a high level of PD are Malaysia, Slovakia, Guatemala, Panama, Philippines, 
Russia, Arab countries, India, China, and Poland. Examples of some countries with a low PD level are New Zealand, Australia, Scandinavian countries, and Israel. Inhabitants of these countries tend to be less tolerant of authorities and rely on facts in decision-making without expecting detailed information on what to do (Leonard et al., 2011).

This may lead to preferred forms of communication and content. Representatives of cultures with a high PD level will be more likely to accept direct guidelines and will be more tolerant of regulations and the limitations of a given medium (SM), a discussion group, or an SM profile. People from cultures with a low PD level will better tolerate an informal language of communication, the possibility of dialogue, and a chance to express one's opinion, thus:

H3: Representatives of cultures with a higher level of PD use SM less frequently.

\subsection{Masculinity (MAS) and femininity}

The dimension of masculinity and femininity is linked to the classification of societies into those that clearly separate gender roles and those that blur gender borders between women and men. In highly masculine cultures, communities are characterized by high competition, assertiveness, materialism, striving for power and promotion, and ambition (e.g. Ireland, Great Britain, South Africa, the United States, Australia, Slovakia, Hungary, Austria, Italy, Germany, Poland, Japan, China, and the Philippines). In feminine cultures appears a tendency to balance out the roles played by men and women: both may perform similar professional and social functions. The basic values of feminine cultures are relationship cultivation, solidarity, service, emotions, mutual care, and quality of life (e.g. Sweden, Norway, Denmark, Portugal, Spain, France, Latvia, Slovenia, Lithuania, Estonia, Thailand, South Korea, and Vietnam) (Hofstede, 2011, Wen Gong, Stump Zhan, 2014).

Therefore, we may assume that SM will attract more interest from cultures with a higher level of femininity, in order to build relationships, help others, and share emotions; hence:

H4: High levels of MAS have a negative impact on the level of SM use.

\subsection{Short-Term and Long-Term Orientation (LTO)}

The LTO dimension indicates the differences in the perception of the future and inclination to assure prosperity in the long run (Hofstede, Bond, 1988). Typical for the LTO are preventive behaviors like saving or rational management of resources, but also persistence, systematic action, and pragmatism (e.g. Japan, South Korea, China, Ukraine, Germany, Estonia, Belgium, Lithuania, and Russia). Short-term-oriented cultures focus on the present and the past, and they pay attention to tradition, patriotism, and are more prone to fundamentalism; they expect actions 
to have prompt effects (e.g. Ghana, Egypt, Nigeria, Colombia, Iran, Morocco, Zimbabwe, Venezuela, Georgia, Finland, Israel, and Poland).

Long-term oriented cultures require communication styles that build mutual relations. Their representatives believe relations are more important than precise information exchange. If some words may harm a group or threaten someone's dignity, one should not use these words. On the other hand, short-term-oriented cultures especially value effective and adequate messages. Therefore, in social marketing, media that ensure interaction may be more effective in markets with a dominant long-term orientation, whereas media that enable the transmission of fast, accurate messages should succeed in the case of short-term-orientated markets; hence:

H5: SM are more commonly used by representatives of long-term-oriented cultures.

\subsection{Restraint and Indulgence (IN)}

Leniency characterizes societies that allow for a relatively casual fulfillment of human desires connected with enjoying life and entertainment (e.g. Mexico, Sweden, New Zealand, Australia, USA, Colombia, Nigeria, and Ghana). Restraint is a feature of societies that suppress the satisfaction of needs and regulate them by means of strict social norms (e.g. Egypt, Hong Kong, South Korea, China, Poland, Morocco, and India) (Hofstede Insight, 2019).

The level of IN may have a significant impact on the choice of SM used by representatives of a culture and the behaviors on an SM platform itself. SM services that allow for more hedonistic attitudes, the presentation of one's experiences, and links with entertainment or controversial topics are likely to attract more interest in countries with a lenient culture. Restraint cultures will incline towards SM that allow for more privacy and conservative content; hence:

H6: SM are used less frequently in cultures with a higher restraint level.

\section{Method}

In order to determine how a national culture influences the frequency of SM usage, a secondary data study was conducted. As a dependent variable, it was assumed the percentage of SM users from DataReportal in January 2019. Among the analyzed countries, the highest rate of SM users was 99\% for the United Arab Emirates, and the lowest was 12\% for Nigeria; the median was $65.50 \%$ and the average $60.91 \%$. Dependent variables were indicators that described the levels of six dimensions of national cultures developed by Hofstede Insight for 44 countries, including 25 with high income levels $(>12,376 \$)$, ten with above-average income levels $(>3,996-12,375 \$)$ and nine with below-average income levels $(<3,996 \$$; according to the 
World Bank classification in data from August 2019). The list of countries was established on the basis of the report Digital 2019: Global Digital Yearbook from January 2019.

The statistical analysis was performed with IBM SPSS 25. The significance level was set at 0.05 , but the results from the range of $0.05<\mathrm{p}<0.1$ were considered significant at the level of the statistical trend due to the low sample size $(n=44)$.

\section{Results}

Preceding the regression analysis, the analysis of scatter plots for cultural dimensions and the dependent variable found that the relation for LTO is curvilinear. No similar phenomenon was observed for the other variables. Therefore, in order to better match the model, the study applied a third-degree polynomial regression analysis. In the case of only two variables dependent (\% of SM users) and independent (LTO) in the form of a third-degree polynomial regression model - the value of $\mathrm{R}^{2}$ was $36.3 \%$, which indicates a good level of curve adjustment to the empirical data. In comparison, $\mathrm{R}^{2}$ for a regression equation that only takes into account a linear relationship (illustrated in the graph by the straight line) explains only $8.8 \%$ of the variance in the dependent variable.

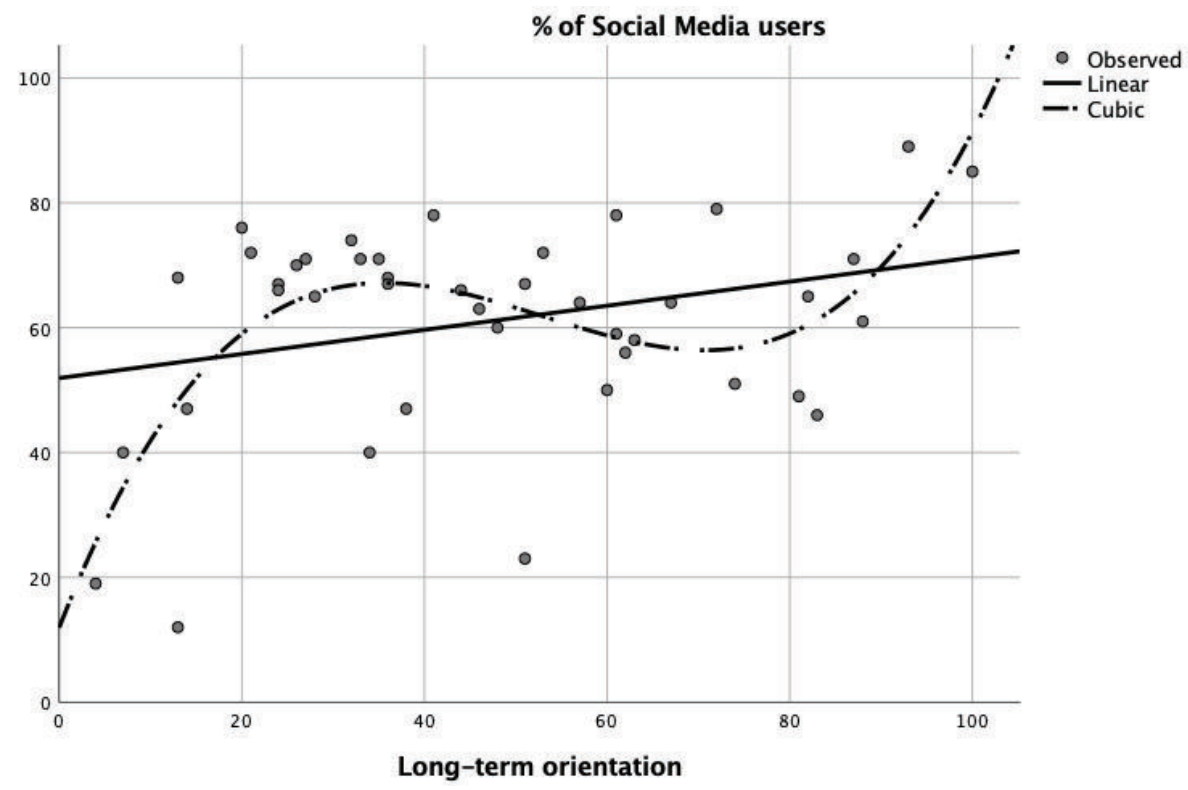

Figure 1. Long-term orientation and percentage of SM users; scatter plots and linear and cubic regression lines

Source: own elaboration. 
As we may observe, a positive correlation occurs in the case of cultures with a very low LTO level (below 20) and also with a high level (above 80). In both cases, the increase in the indicator results in an increase in the percentage of SM users. For cultures with moderate LTO, the curve changes direction and becomes slightly negative, which indicates that the increase in long-term orientation in this section is associated with a decrease in the number of SM users. We should underline here that this applies to countries with an already relatively high proportion of SM users, mostly between 60 and $80 \%$. The reduction in growth may occur due to other than cultural determinants, which are not the subject of this study. The above analysis allows for partial confirmation of the hypothesis H5: SM is more commonly used by representatives of long-term-oriented cultures.

Since income in a given country may be a factor that can significantly impact the percentage of SM users, the study conducted a regression analysis to check the impact of this factor on high (I3), medium-higher (I2), and medium-lower (I3) income countries. A summary of the models is presented in the tables below. The first model only considers income in the examined countries, while the second includes variables that represent cultural dimensions, and the third introduces two second- and third-degree polynomials for LTO to capture the curvilinearity.

The results obtained in model 1 indicate the relevance of including the income level variable, as lower-income countries have a lower percentage of SM users than wealthy countries (D3), which serve as a benchmark. However, there is no difference between the highest income countries and those with higher average incomes. $\mathrm{R}^{2}$ for model 1 explains $38.4 \%$ of the dependent variable's variance.

Model 2 explains 54.9\% of the dependent variable's variance, but it also considers the dimensions of culture as predictors. In this model, the LTO variable turns out to be not statistically significant $(p=0.714)$, which is the result of the non-linear nature of the dependency, which is not included here. The two dimensions of culture are significant at the level of the statistical trend of IND $(p=0.094)$ and UA $(p=0.065)$. The direction of the obtained relation is u-shaped. These results allow us to verify hypotheses $\mathrm{H} 1$ and $\mathrm{H} 2$ when controlling the level of income. The $\mathrm{H} 1$ hypothesis that collectivist cultures use SM more frequently has been confirmed, because the higher the IND indicator, the lower the frequency of media usage. On the other hand, the H2 hypothesis about the high levels of UA is associated with higher levels of SM usage and should be rejected. The results indicate that cultures with a higher UA rating are less likely to use SM. This may be due to the fact that SM are perceived as a new medium of communication, so they appear as not fully worth trusting with the information they convey. 
Table 1. The results of the regression analysis of the scale of SM usage in relation to the dimensions of national culture

\begin{tabular}{|c|c|c|c|c|c|c|c|c|c|}
\hline \multicolumn{10}{|c|}{ Model Summary } \\
\hline \multirow[b]{2}{*}{ Model } & \multirow[b]{2}{*}{$\mathrm{R}$} & \multirow[b]{2}{*}{ R-square } & \multirow[b]{2}{*}{$\begin{array}{l}\text { adjusted } \\
\text { R-square }\end{array}$} & \multirow[b]{2}{*}{$\begin{array}{l}\text { Standard Error } \\
\text { of the estimate }\end{array}$} & \multicolumn{5}{|c|}{ Change statistics } \\
\hline & & & & & $\begin{array}{l}\text { R-square } \\
\text { change }\end{array}$ & F change & df1 & $\mathrm{df} 2$ & $\begin{array}{l}\text { Sig. F } \\
\text { change }\end{array}$ \\
\hline 1 & $0.619^{\mathrm{a}}$ & 0.384 & 0.352 & 14.869 & 0.384 & 12.131 & 2 & 39 & 0.000 \\
\hline 2 & $0.741^{\mathrm{b}}$ & 0.549 & 0.439 & 13.831 & 0.165 & 2.013 & 6 & 33 & 0.092 \\
\hline 3 & $0.798^{\mathrm{c}}$ & 0.636 & 0.519 & 12.811 & 0.088 & 3.732 & 2 & 31 & 0.035 \\
\hline \multicolumn{10}{|c|}{$\begin{array}{l}\text { a Predictors: (Constant), I2, I1, } \\
\text { b Predictors: (Constant), I2, I1, MAS, UA, IN, LTO, IND, PD. } \\
\text { c Predictors: (Constant), I2, I1, MAS, UA, IN, LTO, IND, PD, LTO }{ }^{3}, \mathrm{LTO}^{2} \text {. }\end{array}$} \\
\hline
\end{tabular}

\begin{tabular}{|c|c|c|c|c|}
\hline \multicolumn{5}{|c|}{ Coefficients } \\
\hline & \multirow{2}{*}{ Model } & \multicolumn{2}{|c|}{ Unstandarized coefficients } & \multirow{2}{*}{ Significance } \\
\hline & & $\mathrm{B}$ & Standard error & \\
\hline \multirow{3}{*}{1} & (Constant) & 67.200 & 3.045 & 0.000 \\
\hline & I1 & -28.533 & 5.920 & 0.000 \\
\hline & $\mathrm{I} 2$ & -2.000 & 5.698 & 0.727 \\
\hline \multirow{9}{*}{2} & (Constant) & 99.160 & 20.188 & 0.000 \\
\hline & I1 & -41.813 & 7.961 & 0.000 \\
\hline & $\mathrm{I} 2$ & -9.181 & 6.486 & 0.166 \\
\hline & PD & 0.113 & 0.154 & 0.467 \\
\hline & IND & -0.229 & 0.133 & 0.094 \\
\hline & MAS & -0.138 & 0.130 & 0.297 \\
\hline & UA & -0.194 & 0.102 & 0.065 \\
\hline & LTO & -0.040 & 0.109 & 0.714 \\
\hline & IN & -0.053 & 0.130 & 0.687 \\
\hline \multirow{11}{*}{3} & (Constant) & 68.847 & 23.255 & 0.006 \\
\hline & I1 & -34.879 & 8.001 & 0.000 \\
\hline & I2 & -9.029 & 6.023 & 0.144 \\
\hline & PD & 0.128 & 0.146 & 0.388 \\
\hline & IND & -0.190 & 0.133 & 0.164 \\
\hline & MAS & -0.149 & 0.121 & 0.228 \\
\hline & UA & -0.189 & 0.101 & 0.071 \\
\hline & LTO & 2.278 & 0.964 & 0.025 \\
\hline & IN & -0.041 & 0.122 & 0.738 \\
\hline & $\mathrm{LTO}^{2}$ & -0.054 & 0.020 & 0.013 \\
\hline & $\mathrm{LTO}^{3}$ & 0.000 & 0.000 & 0.010 \\
\hline
\end{tabular}

Dependent variable: percent of SM users.

Source: own elaboration. 
Model 3 considers the non-linear nature of the relationship between the LTO and the percent of SM users and explains $63.6 \%$ of the dependent variable's variance. In this case, the LTO variables $(p=0.025 ; b=2.278)$ and the UA variables $(p=0.071 ; b=-0.189)$ significantly impact the percentage of SM users. The conclusions of this model confirm the earlier verification of the $\mathrm{H} 2$ and $\mathrm{H} 5$ hypotheses.

\section{Conclusions and Discussion}

The analysis of the relationship between the dimensions of national cultures and the degree of SM usage shows a significant relationship between the LTO, IND, and UA levels and the percentage of SM users in a given country. However, the research found no significant influence of MAS, IN, and PD dimensions.

The Wen Gong and Stump Zhan (2014) study on a sample of 36 countries similarly shows no impact of IG on the scale of SM usage but confirms UA dependency: high UA is found in countries in which SM use is lower. However, other conclusions differ from the current study. Wen Gong and Stump Zhan (2014) do not demonstrate the impact of the IND level on the percent of SM users, while the present study shows a significant dependence of the IND level on the model that controls the wealth impact of a country. Moreover, Wen Gong and Stump Zhan also show a correlation between the level of MAS and the percent of SM users, while the current study finds no such significant links. Furthermore, on the basis of a smaller sample of countries, Wen Gong and Stump Zhan show the existence of a negative relationship between the IP level and the percentage of SM users. The gap may be due to the small sample size, which could mainly consist of countries with an average level of the IP. This interpretation would confirm the conclusions of the third-degree polynomial regression model, in which the IP has a minor but negative impact in the middle of the obtained curve. In a survey across a sample of 22 European countries, Gravili and Fait (2016) confirm the existence of a negative relationship among the levels of LTO, PD, UA, and MAS, whereas a positive relationship of the level of IN and the percent of SM users, but also the lack of relevance of the level of IND.

The reported discrepancies are most likely related to the use of different test samples. However, the current study claims to be the most comprehensive, as it was conducted on the most diverse sample of all the available research. As the three estimated models gradually become increasingly complex, they show that it is very important to consider the economic factor of income in a given economy in the overview of SM use. However, the analysis of the 
cultural factors' impact on SM use and its conclusions may certainly turn out erroneous and incomplete.

The literature review in the current study showed that previously conducted analyses of cultural factors are quite narrow, often unrepresentative, and containing divergent results about the influence of cultural dimensions on the scale of SM use. This indicates the need to conduct further research to assess existing conditions better, but also to identify trends and predict the future directions of SM and their users' development.

\section{References}

Brewer, P., Venaik, S. (2011). Individualism-collectivism in Hofstede and GLOBE. Journal of International Business Studies, 42 (3), 436-445.

Ess, C., Sudweeks, F. (2005). Culture and Computer-Mediated Communication: Toward New Understandings. Journal of Computer-Mediated Communication, 11 (1), 179-191. DOI: 10.1111/j.1083-6101.2006.tb00309.x.

Goodricha, K., de Mooijb, M. (2013). How 'social' are social media? A cross-cultural comparison of online and offline purchase decision influences. Journal of Marketing Communications, 20 (1-2), 103-116. DOI: 10.1080/13527266.2013.797773.

Gudykunst, W.B. (1997). Cultural Variability in Communication. Communication Research, 24 (40), 327-348. DOI: 10.1177/009365097024004001.

Halavais, A. (2000). National borders on the world wide web. New Media and Society, 2 (1), 7-28. DOI: $10.1177 / 14614440022225689$.

Hermeking, M. (2006). Culture and Internet Consumption: Contributions from Cross-Cultural Marketing and Advertising Research. Journal of Computer-Mediated Communication, 11 (1), 192-216. DOI: 10.1111/j.1083-6101.2006.tb00310.x.

Hofstede, G. (1983). The cultural relativity of organizational practices and theories. Journal of International Busines Studies, 14 (2), 75-89. DOI: 10.1057/palgrave.jibs.8490867.

Hofstede, G. (2000). Kultury i organizacje: zaprogramowanie umystu. Warszawa: PWE.

Hofstede, G. (2011). Dimensionalizing Cultures: The Hofstede Model in Conntext. Online Readings in Psychology and Culture, 2 (1), 1-26. DOI: 10.9707/2307-0919.1014.

Hofstede, G., Bond, M. (1988). The Confucius connection: from cultural roots to economic growth. Organizational Dynamics, 16 (4), 5-21

Hofstede, G., Hofstede, G. (2007). Kultury i organizacje. Warszawa: PWE. 
Hsu, M.-H., Chang, C-M., Lin, H-C., Lin, Y-W. (2015). Determinants of continued use of social media: the perspectives of uses and gratifications theory and perceived interactivity. Information Research, 20 (2), paper 671. Retrieved from: http://nformationR.net/ir/20-2/ paper671.html (Archived by WebCite ${ }^{\circledR}$ at http://www.webcitation.org/6ZG2FYK7I).

Hyrokawa, K., Dohi, I., Vannieuwennhuyse, B., Miyata, Y. (2001). Comparison of French and Japanese Individuals With Reference To Hofstede'S Concepts of Individualism and Masculinity. Psychological Reports, 89, 243-251. DOI: 10.2466/pr0.2001.89.2.243.

Krawuczka, A. (2014). Uwarunkowania kulturowe w marketingu międzynarodowym. Przegląd Nauk Stosowanych; Aspekt Kulturowy Międzynarodowego Biznesu, 3, 19-29.

Leibbrandt, A., Gneezy, U., List, J.A. (2013). Rise and fall of competitiveness in individualistic and collectivistic societies. Proceedings of the National Academy of Sciences, 110 (23), 9305-9308. DOI: 10.1073/pnas.1300431110.

Leonard, K.M., Van Scotter, J.R., Pakdil, F., Chamseddine, N.J., Esatoglu, E., Gumus, M., Koyuncu, M., Wu, L.L., Mockaitis, A.I., Salciuviene, L., Oktem, M.K., Surkiene, G., Tsai, F.S. (2011). Examining media effectiveness across cultures and national borders: A review and multilevel framework. International Journal of Cross Cultural Management, 11 (1), 83-103. DOI: 10.1177/1470595810389790.

Schwartz, S.H. (1994). Beyond individualism/collectivism: New cultural dimensions of values. In: U. Kim, H.C. Triandis, Ç. Kâğitçibaşi, S.-C. Choi, G. Yoon (eds.), Cross-cultural research and methodology series, Vol. 18. Individualism and collectivism: Theory, method, and applications (pp. 85-119). Thousand Oaks, CA, US: Sage Publications, Inc.

Shachaf, P., Snyder, M. (2007). The Relationship Between Cultural Diversity and User Needs in Virtual Reference Services. Journal of Academic Librarianship, 33 (3), 361-367. DOI: 10.1016/j.acalib.2007.01.012.

Soares, A.M., Farhangmehr, M., Shoham, A. (2007). Hofstede's dimensions of culture in international marketing studies. Journal of Business Research, 60 (3), 277-284. DOI: 10.1016/j.jbusres.2006.10.018.

Social Media and SMEs: A Comparison among Generations (2016). G. Gravili, M. Fait, (ed.), Social Recruitment in HRM (The Changing Context of Managing People) (pp. 39-71). Emerald Group Publishing Limited.

Tavanti, M. (2012). The cultural dimensions of Italian leadership: Power distance, uncertainty avoidance and masculinity from an American perspective, Leadership, 8 (3), 287-301. DOI: $10.1177 \% 2 F 1742715012441876$.

Wen Gong Rodney, L., Stump Zhan, G. Li (2014). Global use and access of social networking web sites: a national culture perspective. Journal of Research in Innteractive Marketing, 8 (1), 37-55. DOI: 10.1108/JRIM-09-2013-0064.

World Bank Country and Lending Groups. Retrieved from: https://datahelpdesk.worldbank.org/ knowledgebase/articles/906519-world-bank-country-and-lending-groups (15.08.2019). 
Hofstede Insights (2019). Retrieved from: https://www.hofstede-insights.com/product/compare-countries (10.08.2019).

Digital (2019). Global Digital Yearbook. Retrieved from: https://datareportal.com/reports/ digital-2019-global-digital-yearbook?utm_source=Reports\&utm_medium=PDF\&utm_ campaign=Digital_2019\&utm_content=Global_Overview_Promo_Slide (20.02.2019). 